\title{
Recurrent Transmission of a 17q12 Microdeletion and a Variable Clinical Spectrum
}

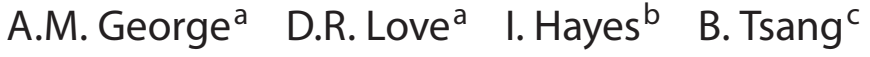 \\ ${ }^{a}$ Diagnostic Genetics, LabPlus, and ${ }^{b}$ Northern Regional Genetic Service, Auckland City Hospital, and \\ 'Department of Paediatrics, North Shore Hospital, Auckland, New Zealand
}

\section{Key Words}

Deletion of $17 q 12 \cdot$ Developmental delay $\cdot$ Diabetes

mellitus $\cdot$ Renal cysts

\begin{abstract}
The relatively rare proximal microdeletion of $17 q 12$ (including deletion of the HNF1B gene) is associated with the renal cysts and diabetes syndrome. Recent reports have suggested that there may also be an association between this microdeletion and learning difficulties/autism. This case report describes one of only a few reported families segregating the 17q12 microdeletion, but which highlights the nonpenetrance and variable expressivity of multiple features of this condition.

Copyright $\odot 2011$ S. Karger AG, Basel
\end{abstract}

The renal cysts and diabetes (RCAD) syndrome (OMIM 137920) is an autosomal dominant disorder. It comprises nondiabetic renal disease resulting from abnormal renal development, and diabetes. In some cases diabetes occurs earlier than 25 years of age and is therefore consistent with a diagnosis of maturity-onset diabetes of the young (MODY; OMIM 606391). Haploinsufficiency of the hepatocyte nuclear factor 1B (HNF1B; OMIM 189907) has been shown to be causative of RCAD syndrome. Deletion of the entire gene, deletion of 1 exon and small mutations of $H N F 1 B$ are all associated with the RCAD phenotype [Heidet et al., 2010]. Mefford et al. [2007] identified a recurrent $1.5-\mathrm{Mb}$ de novo deletion in $17 \mathrm{q} 12$ encompassing the $H N F 1 B$ gene that results in phenotypes ranging from congenital renal abnormalities to MODY type 5. Variable expressivity of renal disease and diabetes has been noted in many families with this condition and affected individuals may also have abnormalities of the genital tract. Only 2 of 19 cases have shown parental transmission, and in each of these cases, the parent and affected offspring exhibited a similar phenotype.

Recent reports have suggested that there may also be a link between the 17q12 microdeletion and intellectual impairment/autism, although information regarding how common these complications occur in carriers of the deletion is currently not known. This case report describes a family segregating the $17 \mathrm{q} 12$ microdeletion associated with renal disease and intellectual impairment, but with variability in penetrance/expressivity.

\section{Case Report}

The proband is a 7-year-old female with attention deficit, hyperactivity, disruptive behavior and learning difficulties. Physical examination and growth were normal: weight $24.5 \mathrm{~kg}$ (75th percentile), height $122 \mathrm{~cm}$ (50th percentile) and head circumference $53.5 \mathrm{~cm}$ (75-90th percentile). Although immature, language, social reciprocity and mood were normal. General cognitive ability

\section{KARGER}

Fax +4161306 1234

E-Mail karger@karger.ch

www.karger.com (c) 2011 S. Karger AG, Basel

$1661-8769 / 11 / 0022-0072 \$ 38.00 / 0$

Accessible online at:

www.karger.com/msy
Alice George

Diagnostic Genetics, LabPlus

Auckland City Hospital

PO Box 110031, Auckland 1148 (New Zealand)

Tel. +64 9307 4949, ext. 6396, E-Mail aliceg@adhb.govt.nz 
was within the 'low average range' of intellectual function (19th percentile) as measured by Full scale IQ derived from the 10 subtest scores on the Wechsler Intelligence Scale for Children (Australia) - 4th edition. Function may have been significantly affected by social stressors and improvements were observed on stimulant medication and placement with an alternative caregiver. Family history of learning problems prompted referral to a clinical genetics service for evaluation. No renal tract abnormalities were noted on ultrasound.

She has 1 sibling, a 2.5 -year-old male with mild developmental delay and bilateral renal cystic disease. An antenatal ultrasound scan at 30 weeks of gestation showed that 1 kidney was larger than the other. A 5-day postnatal scan revealed multiple cysts in both kidneys. Repeat ultrasound at 9 months of age revealed echogenic kidneys with multiple small bilateral renal cysts thought to represent cystic dysplasia. Infantile presentation of autosomal dominant polycystic kidney disease was also considered but thought less likely. His growth was normal, weight $12.7 \mathrm{~kg}$ (50th percentile), height $82.2 \mathrm{~cm}$ (25th percentile), and no detail on head circumference was given. He had isolated mild gross motor delay achieving sitting at 9 months of age.

The proband's father had significant learning difficulties as a child and is unable to read or write. He has 1 brother with low normal intelligence who stutters, and his mother has learning difficulties, too. The proband's mother has learning difficulties of a lesser degree compared to the father and is able to read and write, but she is adopted and there is very little known about her extended family history. Both parents were in special needs classes at school and have never been in employment. No behavioral issues were noted in either of them. There is no known extended family history of renal disease or early onset diabetes in either family. Both parents have had normal renal ultrasounds, random blood glucose and hemoglobin $\mathrm{Alc}\left(\mathrm{HbA}_{1 \mathrm{c}}\right)$ results.

\section{Materials and Methods}

A DNA sample was initially obtained from the 7-year-old proband for genome-wide copy number analysis using the Affymetrix ${ }^{\circledR}$ Cytogenetics Whole-genome $2.7 \mathrm{M}$ array, according to manufacturer's instructions. Regions of copy number variation (CNV) were identified using the Affymetrix Chromosome Analysis Suite software (ChAS) v.1.0.1 and interpreted with the aid of UCSC genome browser (http://gemome.ucsc.edu/; Human Mar. 2006 (hg18) assembly). The male sibling and both parents were subsequently tested using the same methodology.

\section{Results}

The array analysis of the proband revealed a $1.4-\mathrm{Mb}$ heterozygous deletion involving interstitial chromosome region 17q12 (coordinates of the deleted region chr17: 31,923,035-33,323,544; fig. 1). The deletion was also detected in the male sibling, thereby conferring an obligate carrier status on one of the parents. The array result for the father of our proband revealed no CNVs, while the mother carried a sole $\mathrm{CNV}$ that corresponded to the same $17 \mathrm{q} 12$ deletion as her affected son and daughter. The deletion is likely to be caused by nonallelic homologous recombination involving nonrepetitive sequences with a high (at least 90\%) level of homology (fig. 1).

\section{Discussion}

The 17q12 deletion phenotype comprises some, all or none of the following features: renal abnormalities including cysts; genital tract anomalies; MODY type 5 diabetes mellitus; mild dysmorphic features; and developmental delay with or without behavioral problems. The majority of cases of RCAD caused by mutation or deletion of the $H N F 1 B$ gene reported in the literature are intellectually normal with renal disease and/or MODY. In contrast, multiple members of the family in our case report exhibited developmental delay, behavioral issues and learning difficulties.

One case with a de novo 17q12 microdeletion and genital anomalies has been described who had severe learning disability and seizures, without diabetes or renal malformations [Cheroki et al., 2008]. An investigation of a cohort of 53 children with renal cysts and deletion of the entire $H N F 1 B$ gene revealed 3 to carry a de novo deletion; these 3 children showed early onset developmental delay and social interaction impairments concordant with autism [Loirat et al., 2010]. Of 4 further patients who were investigated due to renal disease, 3 exhibited developmental delay; parental studies were only available for 1 case, which confirmed a de novo deletion [Nagamani et al., 2010]. Studies by Moreno-De-Luca et al. [2010] of individuals affected with neurodevelopmental disorders identified 18 patients with a recurring $1.4-\mathrm{Mb}$ deletion of $17 \mathrm{q} 12$; parental information was available for 8 patients, one of which had a maternally inherited deletion. The mother was affected with bipolar disorder, diabetes and kidney cysts. Ascertainment bias should be taken into consideration where the studies targeted specific groups, namely those patients with renal cysts [Cheroki et al., 2008] or neurodevelopmental disorders [Moreno-De-Luca et al., 2010]. Analysis of several large populations indicated a statistically significant risk of associated neurodevelopmental disorders and RCAD [Moreno-De-Luca et al., 2010]. Detailed patient information is available on 26 patients from 5 earlier studies [Mefford et al., 2007; Bernardini et al., 2009; Loirat et al., 2010; Moreno-De-Luca et al., 2010; Nagamani et al., 2010]. Features in common were genitourinary tract anomalies including renal cysts, mild to moder- 


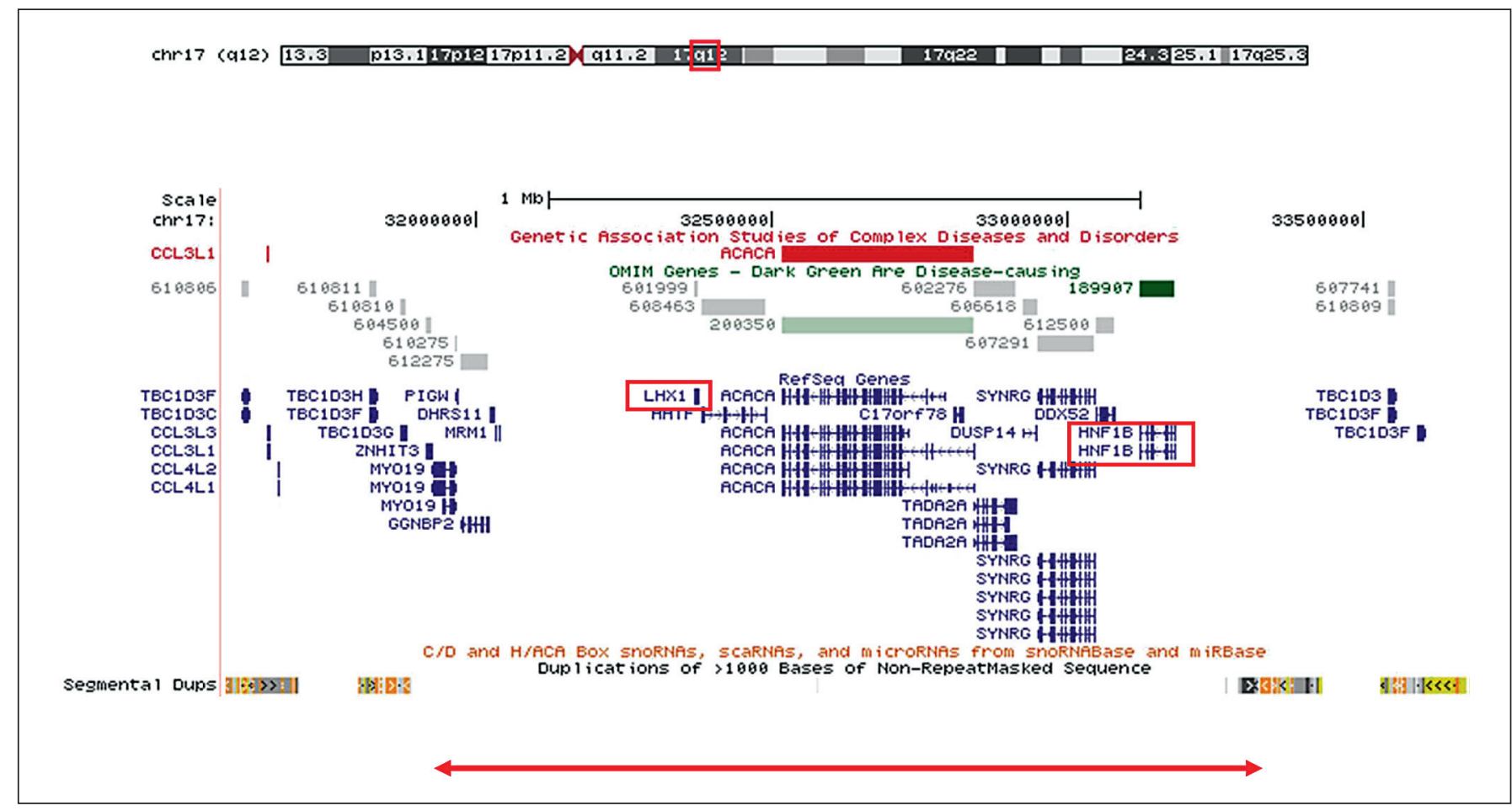

Fig. 1. Location and extent of chromosome 17q12 microdeletion. A UCSC Genome Browser (March 2006 (hg18) assembly) view of the flanking region of chromosomal region 17q12 (chr17: $31,572,908-33,673,672)$ is shown, together with OMIM genes,
Refseq genes, short regulatory RNAs and segmental duplications. The bottom panel shows the location and extent of the $1.4-\mathrm{Mb}$ microdeletion detected in the proband reported here $(31,923,035-$ $33,323,544)$. ate neurocognitive delay mainly affecting speech, and several cases of macrocephaly or mild dysmorphic features. Our family shared the neurocognitive delay but had no dysmorphic features or macrocephaly of note and only 1 out of the 3 family members had renal cysts.

There are multiple confounding factors in our family that make it difficult to assign a strong association between the microdeletion and learning delay. The father had intellectual impairment without carrying the deletion. In addition, the absence of a family history in the mother who carries the microdeletion makes interpretation of the cause of her learning problems difficult.

Of the 15 genes localized to the $17 \mathrm{q} 12$ microdeletion region, 2 may play a role in the variable phenotypes seen in affected carriers. Expression of the HNF1B gene is associated with vertebrate hindbrain development [Chomette et al., 2006; Pouilhe et al., 2007] and the translation product of this gene, hepatocyte nuclear factor-1, guides the embryological development of the kidneys, pancreas, liver and Müllerian ducts [Bingham and Hattersley, 2004]. LHX1 is a candidate gene for the learning difficulties. Animal models have shown this gene to be an essen- tial regulator of the vertebrate head organizer and to be also expressed in the developing kidney [Shawlot and Behringer, 1995]. Expression of the mouse Lhxl gene has also been shown to be involved in the developmental processes of the genitourinary system, including the Müllerian ducts [Kobayashi et al., 2005]. It is required for migration of motor axons to the limb [Kania et al., 2000], may be involved in Purkinje cell development in the cerebellum [Zhao et al., 2007], and knockout mice exhibit anencephaly [Shawlot and Behringer, 1995]. Linkage studies of autism have identified a susceptibility locus in 17q11-17q21 [Kumar and Christian, 2009].

As with both monogenic and contiguous gene disorders, the 17q12 deletion genotype:phenotype correlation is highly variable. This variation in phenotype is suggestive of incomplete penetrance and variable expressivity, which is seen in our case. Several monogenic diseases including Bardet-Biedl syndrome (OMIM 209900) [Katsanis, 2004] and nephronopthisis (OMIM 25610) [Hoefele et al., 2007] are oligogenic where multiple rare variants interact genetically to modify or cause disease expression [Sykiotis et al., 2010]. Contiguous gene disorders such as the $16 \mathrm{p} 11.2$ dele- 
tion syndrome (OMIM 611913) also show considerable variability [Ballif et al., 2007], with a 'second hit' possibly affecting severity. Girirajan et al. [2010] suggest that this could be another $\mathrm{CNV}$, a small disruptive mutation in a related gene, an environmental event leading to alteration in gene dosage, or the creation of a fusion gene. This 2-hit scenario may also explain the comorbidity which exists between cognitive impairment, autism and schizophrenia, in addition to the previously mentioned variation associated with microdeletion/duplication syndromes [Fombonne, 2002; Sharp et al., 2008; Woodberry et al., 2008].

Our case illustrates the unlikely probability of the modifier being a second CNV. There were no additional $\mathrm{CNV}$ calls in any of the family members, which strongly suggests a modifier of unknown origin as previously reported in thrombocytopenia-absent radius syndrome (OMIM 274000) [Klopocki et al., 2007]. There may be a smaller $\mathrm{CNV}$ occurring elsewhere in the genome, below the resolution detected by Affymetrix arrays, and conferring a transcription-related, neurodevelopmental or receptor function that exacerbates the effect of the 17q12 deletion in the offspring [Nord et al., 2011]. Alternatively, there may be a relatively common variant or polymorphism which acts as trigger.

Despite the points mentioned above, the variation in severity of the disease warrants the close surveillance of deletion carriers; the renal disease can range from asymptomatic to requiring transplant or dialysis dependence [Edghill et al., 2008]. The MODY type 5 diabetes mellitus is an autosomal dominant form of nonketotic diabetes mellitus with a typical onset of 25 years of age. The carrier mother is now 27 years old and should be carefully monitored.

\section{References}

Ballif BC, Hornor SA, Jenkins E, Madan-Khetarpal S, Surti U, et al: Discovery of a previously unrecognized microdeletion syndrome 16p11.2-p12.2. Nat Genet 39:1071-1073 (2007).

-Bernardini L, Gimelli S, Gervasini C, Carell M, Baban A, et al: Recurrent microdeletion at $17 q 12$ as a cause of Mayer-RokitanskyKuster-Hauser (MRKH) syndrome: two case reports. Orphanet J Rare Dis 4:25 (2009).

-Bingham C, Hattersley AT: Renal cysts and diabetes syndrome resulting from mutations in hepatocyte nuclear factor-1B. Nephrol Dial Transplant 19:2703-2708 (2004).

$\checkmark$ Cheroki C, Krepichi-Santos AC, Szuhai K, Brenner V, Kim CA, et al: Genomic imbalances associated with mullerian aplasia. J Med Genet 45:228-232 (2008).

Chomette D, Frain M, Cereghini S, Charnay P, Ghislain J: Krox20 hindbrain cis-regulatory landscape: interplay between multiple longrange initiation and autoregulatory elements. Development 133:1253-1262 (2006).

Edghill EL, Oram RA, Owens M, Stals KL, Harries LW, et al: Hepatocyte nuclear factor-1beta gene deletions - a common cause of renal disease. Nephrol Dial Transplant 23:627-635 (2008).

Fombonne E: Epidemiological trends in rates of autism. Mol Psychiatry 7 Suppl 2:S4-6 (2002).

-Girirajan S, Rosenfeld JA, Cooper GM, Antonacci F, Siswara P, et al: A recurrent 16p12.1 microdeletion supports a two-hit model for severe developmental delay. Nat Genet 42:203210 (2010).

- Heidet L, Decramer S, Pawtowski A, Morinière $\mathrm{V}$, Bandin F, et al: Spectrum of HNF1B mutations in a large cohort of patients who harbor renal diseases. Clin J Am Soc Nephrol 5: 1079-1090 (2010).
Hoefele J, Wolf MT, O’Toole JF, Otto EA, Schultheiss U, et al: Evidence of oligogenic inheritance in nephronophthisis. J Am Soc Nephrol 18:2789-2795 (2007).

Kania A, Johnson RL, Jessell TM: Coordinate roles for LIM homeobox genes in directing the dorsoventral trajectory of motor axons in the vertebrate limb. Cell 102:161-173 (2000).

Katsanis N: The oligogenic properties of BardetBiedl Syndrome. Hum Mol Genet 1:R65-71 (2004).

Klopocki E, Schulze H, Straub G, Ott CE, Hall J, et al: Complex inheritance pattern resembling autosomal recessive inheritance involving a microdeletion in thrombocytopenia-absent radius syndrome. Am J Hum Genet 80:232-240 (2007)

Kobayashi A, Kwan KM, Carroll TJ, McMahon AP, Mendelsohn CL, Behringer RR: Distinct and sequential tissue-specific activities of the LIM-class homeobox gene Lim1 for tubular morphogenesis during kidney development. Development 132:2809-2823 (2005).

Kumar RA, Christian SL: Genetics of autism spectrum disorders. Curr Neurol Neurosci Rep 9:188-197 (2009).

Loirat C, Bellane-Chantelot C, Husson I, Deschenes G, Guigonis V, Chabane N: Autism in three patients with cystic or hyperechogenic kidneys and chromosome 17q12 deletion. Nephrol Dial Transplant 25:3430-3433 (2010).

Mefford HC, Clauin S, Sharp AJ, Moller RS, Ullmann R, et al: Recurrent reciprocal genomic rearrangements of $17 \mathrm{q} 12$ are associated with renal disease, diabetes and epilepsy. Am J Hum Genet 81:1057-1069 (2007).

Moreno-De-Luca D, SGENE consortium, Mulle JG, Simons Simplex Collection Genetics Consortium, Kaminsky EB, et al: Deletion
$17 \mathrm{q} 12$ is a recurrent copy number variant that confers high risk of autism and schizophrenia. Am J Hum Genet 87:618-630 (2010).

Nagamani SC, Erez A, Shen J, Li C, Roeder E, et al: Clinical spectrum associated with recurrent genomic rearrangements in chromosome 17q12. Eur J Hum Genet 18:278-284 (2010).

Nord AS, Roeb W, Dickel DE, Walsh T, Kusenda $M$, et al: Reduced transcript expression of genes affected by inherited and de novo CNVs in autism. Eur J Hum Genet 19:727731 (2011)

-Pouilhe M, Gilardi-Hebenstreit P, DesmarquetTrin Dinh C, Charnay P: Direct regulation of $v H n f 1$ by retinoic acid signaling and MAFrelated factors in the neural tube. Dev Biol 309:344-357 (2007).

-Sharp AJ, Mefford HC, Li K, Baker C, Skinner C, et al: A recurrent $15 \mathrm{q} 13.3$ microdeletion syndrome associated with mental retardation and seizures. Nat Genet 40:322-328 (2008).

Shawlot W, Behringer RR: Requirement for Lim1 in head-organizer function. Nature 374: 425-430 (1995).

-Sykiotis GP, Plummer L, Hughes VA, Au M, Durrani S, et al: Oligogenic basis of isolated gonadotropin-releasing hormone deficiency. Proc Natl Acad Sci USA 107:15140-15144 (2010).

Woodberry KA, Giuliano AJ, Seidman LJ: Premorbid IQ in schizophrenia: a meta-analytic review. Am J Psychiatry 165:579-587 (2008).

Zhao Y, Kwan KM, Mailloux CM, Lee WK, Grinberg A, et al: LIM-homeodomain proteins Lhx 1 and Lhx5, and their cofactor Ldb1, control Purkinje cell differentiation in the developing cerebellum. Proc Natl Acad Sci USA 104:13182-13186 (2007). 